\title{
Feasible utility of inorganic remains from potable water purification process in chemical looping combustion studied in TG
}

\author{
Ewelina Ksepko
}

Received: 10 March 2014/ Accepted: 16 June 2014/Published online: 24 July 2014

(c) The Author(s) 2014. This article is published with open access at Springerlink.com

\begin{abstract}
The objective of the research is to prepare naturally occurring Fe-based materials for use as oxygen carriers and investigate their reactivity in terms of their applicability to energy systems. The inductively coupled plasma optical emission spectrometry test showed that the sediments from potable water purification were largely composed of $\mathrm{Fe}_{2} \mathrm{O}_{3}(57.8-58.1 \%), \mathrm{SiO}_{2}(25.2-30.7 \%)$, $\mathrm{CaO}(3.92-8.43 \%)$, and $\mathrm{Mn}_{3} \mathrm{O}_{4}(0.94-1.39 \%)$. Sediments were examined by cyclic redox experiments in the thermogravimetric analyzer and were compared with reference materials. Gaseous $\left(3 \% \mathrm{H}_{2}\right)$ and solid fuel (hard coal) were tested in terms of chemical looping combustion (CLC). Three cycle tests showed their good reactivity performance. The temperature-depended oxygen transport capacity varied from 4 to $13.9 \%$ by mass. The fairly stable performance was observed during twenty redox cycles. The X-ray powder diffraction patterns after cycling tests showed a stable crystalline phase and confirmed that complete regeneration was achieved, that is contrary to synthetic carriers. Possibly other elements may help to maintain their reactivity and prevented the silicate formation. Scanning electron micrographs of reacted samples showed minor morphology changes. Based on these results, those wastes might be successfully used in a CLC process as efficient and low-cost oxygen carriers.
\end{abstract}

Keywords TG $\cdot$ Chemical looping combustion - Carbon dioxide $\cdot$ Fe-based oxygen carrier $\cdot$ Waste prevention

E. Ksepko $(\bowtie)$

Institute for Chemical Processing of Coal, 1 Zamkowa,

41-803 Zabrze, Poland

e-mail: eksepko@ichpw.zabrze.pl

\section{Introduction}

The chemical looping combustion (CLC) concept has been shown to be a promising technology for effective $\mathrm{CO}_{2}$ capture. In the CLC process, oxygen carriers are used to transport oxygen to fuel instead of the direct mixing of fuel and air. CLC has been described widely elsewhere [1-3]. The significant advantage of a CLC system is that a concentrated $\mathrm{CO}_{2}$ stream can be obtained from the combustion gas stream after water condensation without requiring any energy for separation or purification. In addition, nitrogen oxide $\left(\mathrm{NO}_{x}\right)$ production is greatly reduced [1-5].

In CLC, the agents supplying the oxygen for fuel conversion are oxides or mixtures of various metal oxides. Many potential oxygen carriers are known, including various compositions of copper, manganese, iron, cobalt, or nickel oxides used as active materials, as well as aluminum oxide, titanium dioxide, zirconium dioxide, sepiolite, or bentonite used as inert materials [6-11]. Inert materials are added to extend the oxygen carriers' lifetime by reducing their attrition or improving their thermal resistivity. A suitable oxygen carrier for the CLC process must have high reactivity, high selectivity toward $\mathrm{CO}_{2}$ and $\mathrm{H}_{2} \mathrm{O}$, suitable oxygen transport capacity, high mechanical strength, a low agglomeration tendency, and sufficient attrition resistivity. A successful oxygen carrier must meet those expectations throughout both reduction and oxidation cycles at high temperature in a CLC power plant.

Most of the existing CLC literature has focused on the development of suitable synthetic oxygen carrier materials [2-12]. In these previous works, the authors extensively describe diverse preparation methods and different chemical compositions. Nevertheless, there is little research on naturally occurring chemical looping materials. Recently, some minerals [13-18], industry wastes [18-23], and 
concentrates from minerals [20] have been considered as inexpensive oxygen carriers for CLC. Mostly natural minerals such as ilmenite $\left(\mathrm{FeTiO}_{3}\right)$ have been examined in the past [13-16]. Adanez et al. [13], reported that fresh ilmenite reacted slowly with $\mathrm{H}_{2} / \mathrm{H}_{2} \mathrm{O}, \mathrm{CO} / \mathrm{CO}_{2}$ and $\mathrm{CH}_{4} /$ $\mathrm{H}_{2} \mathrm{O}$. Nevertheless, a gain in the reactivity in reduction/ oxidation was observed with an increase in the number of redox cycles. The initial oxygen transport capacity was measured to be approximately $4 \%$, then decreased as the number of cycles increased, dropping to $2.1 \%$ after 100 redox cycles. Moreover, [22] observed that complete reduction activation was relatively fast with gasification products. Complete activation took place after 6 redox cycles. Using South African coal char at $900{ }^{\circ} \mathrm{C}$, the gasification reaction rate was observed to be enhanced by using ilmenite, compared to the rate obtained using sand. Kolbitsch et al. [14] successfully used that mineral in a $120-\mathrm{kW}$ fuel power dual circulating fluidized bed installation. He investigated the conversion of natural gas and a synthetic gas mixture of $\mathrm{H}_{2}$ and $\mathrm{CO}_{2}$. A reasonable fuel conversion for $\mathrm{CO}$ and $\mathrm{H}_{2}$ at $950{ }^{\circ} \mathrm{C}$ was found, while relatively low (30-40\%) conversion was observed for natural gas. Recently, a few other options for using lower cost, natural-based materials have been investigated in the literature. Ksepko [24] showed potential application of low-cost natural carrier for coal combustion, since the sewage sludge ash was successfully used for direct coal combustion. Also complete regeneration of oxygen carrier was achieved. The X-ray diffraction (XRD) and scanning electron microscopy (SEM) data proved that the Fe-based carrier was coal ash-resistant.

Natural ores, such as iron ore have also been examined [17-20]. Tian et al. [17] observed that chrysocolla (Cubased), hematite, and limonite (Fe-based) demonstrated excellent reactivity and stability in 50-cycle methane CLC thermogravimetric analysis (TG) tests. He also concluded that the $\mathrm{Fe}_{2} \mathrm{O}_{3}$-based ores possessed greater oxygen utilization but required an activation period before achieving full performance in methane CLC. Other studies have indicated the potential of manganese ore [22]. Fossdal et al. [22] tested a manganese ore, selected as a promising carrier for CLC purposes, that showed a maximum oxygen capacity of $4.9 \%$ at $1,000{ }^{\circ} \mathrm{C}$. The addition of an excess of calcium to manganese resulted in the formation of calcium manganite perovskite, which had an oxygen capacity as high as the original ore but presented potential advantages in terms of enhanced kinetics, chemical and mechanical stability and the rate of methane conversion. Remarkably, promising results were also obtained for oxide scales, residual products from rolling steel sheets, that mostly consisted of $\mathrm{Fe}_{2} \mathrm{O}_{3}$ and $\mathrm{Fe}_{3} \mathrm{O}_{4}$ [19, 20]. The residual product showed stable reactivity, demonstrating that good oxygen carriers can also be obtained from waste iron oxide.
Moreover, further studies have even been conducted using material obtained from vehicle recycling, such as Stena Metall. This natural oxygen carrier was mostly composed of $\mathrm{Fe}_{2} \mathrm{O}_{3}$ and $\mathrm{Fe}_{3} \mathrm{O}_{4}$, but some $\mathrm{Si}, \mathrm{Al}$, and $\mathrm{Ca}$ species were also detected. Zhang et al. [23] investigated the $\mathrm{Fe}_{2} \mathrm{O}_{3}$ containing wastes from the steel industry for the CLC of Chinese bituminous coal. The authors observed an increased reactivity and porosity with an increasing number of reduction cycles. After 20 cycles, the concentration of $\mathrm{CO}_{2}$ was higher than $99 \%$, and the carbon conversion increased from 73.45 to $81.41 \%$. Recently, the interest of industry is also to increase both the energy efficiency and to reduce the quantities of fuels that are consumed in the in many manufacturing processes. Some economically friendly examples of using the waste to energy (i.e. scrap tyres) for cement manufacture and their economic, societal, and also environmental benefits are shown elsewhere [25].

The brief overview presented here shows that there is growing interest in the use of naturally occurring oxygen carriers. In light of the multiple interesting aspects, such as their extremely low cost, high availability, lower environmental impact than for $\mathrm{Cu}$ or $\mathrm{Ni}$ oxygen carriers, and potential impact on human health, it would be desirable to identify a suitable candidate for the CLC process. In particular, many challenges are associated with direct coal/ biomass CLC using oxygen carriers. Using a low-cost material as an oxygen carrier would be very desirable due to the partial loss of the carrier with the biomass/coal ash. Moreover, the oxygen carrier should have a sufficient combustion rate to be suitable for various reactor systems, adequate oxygen release capacity enabling the coal-oxygen carrier interactions, and stable reactivity during multiple cycles. High attrition resistance and high melting points would also be highly beneficial.

Encouraging reactivity results have been reported in the literature for naturally occurring oxygen carriers containing Fe species, and therefore, the sediments from the potable water purification process might be considered for practical applications in CLC, as they usually contain iron, manganese, silica, and alumina species [26]. In ground water, iron and manganese are normally present in their bivalent forms, i.e., $\mathrm{Fe}^{2+}$ and $\mathrm{Mn}^{2+}$, which are soluble. Due to exposure to air, the forms are oxidized to the trivalent forms $\mathrm{Fe}^{3+}$ and $\mathrm{Mn}^{3+}$, which are both insoluble and colored. Oxidation and filtration are precipitative processes that are usually applied to remove naturally occurring iron and manganese from water. The processes involve the oxidation of the soluble forms of iron and manganese to their insoluble forms (iron or manganese oxides, and iron or manganese chlorides) and then removal by filtration. Insoluble iron and manganese salts are the cause of "red water" and "black water," respectively. The discoloration of the water is considered aesthetically unpleasant and 
creates objectionable flavors in the water, and therefore, these iron and manganese species are removed in water treatment plants. According to Secondary Drinking Water Regulations by the EPA, the allowed levels for potable water are as follows: $0.3 \mathrm{mg} \mathrm{L}^{-1}$ of iron and $0.05 \mathrm{mg} \mathrm{L}^{-1}$ of manganese [26].

However, no practical use of the waste sediments from the potable water purification process has as yet been reported. Moreover, it would be more economical to use them as oxygen carriers compared to synthetic materials, especially where oxygen carriers have a limited lifetime or could even be lost during circulation in a CLC reactor. Furthermore, sediments from potable water purification process are wastes accompanying human life and are widely present in water treatment plants worldwide. Devising a practical re-use for these sediments would also have both environmental and economic benefits.

The objective of this work was to prepare low-cost oxygen carriers from the water purification process and examine their application for oxygen transfer in CLC. In this work, sediments from the thermal treatment of the inorganic remains from water purification were tested for both gaseous (hydrogen) and solid fuel combustion (direct combustion of hard coal). The hydrogen was used as a fuel in this study, since it is the major compound of syngas from biomass/coal gasification process (among others as $\mathrm{CO}$, $\mathrm{CO}_{2}, \mathrm{CH}_{4}$, etc.). Moreover, the reason for using $\mathrm{H}_{2}$ in the laboratory scale experiments is also to explore the oxygen transfer capacity and stability of the materials under very severe reductive conditions.

TG was used to determine the reaction rates and the percentage of combustion. Multicycle CLC tests were conducted to understand the reaction performance of the oxygen carriers. XRD analysis and ICP-OES tests were conducted to identify their phase and chemical composition. Other physical characterization, such as melting behavior, particle size analysis was also conducted.

\section{Experimental}

Samples preparation

The sediments from potable water purification contained iron species, and they were provided by the Upper Silesian Enterprise of Water Supply Joint Stock from the Upper Silesia region in Poland. Dried excess sludge from deepwater treatment usually contains from $5 \%$ by mass to $95 \%$ by mass of transition metal oxides and was subject to complete burning and grinding to a grain size below $2 \mathrm{~mm}$. The ash obtained was calcined at $850{ }^{\circ} \mathrm{C}$ for $8 \mathrm{~h}$. The thermal treatment was applied to increase the strength of the particles. The calcined sample was sieved through a
$250 \mu \mathrm{m}$ sieve. The powdered sample was brownish-red in color. For comparison purposes, synthetic sediments from the potable water purification process were prepared in the same manner. The reference sample consisted of $58 \%$ by mass $\mathrm{Fe}_{2} \mathrm{O}_{3}, 2 \%$ by mass $\mathrm{Al}_{2} \mathrm{O}_{3}$, and $40 \%$ by mass $\mathrm{SiO}_{2}$ (Sigma Aldrich $>99.8 \%$ ). The synthetic sample composition was due to evaluation and calculation carried out on basis of natural sample composition.

\section{Thermogravimetric analysis}

TG experiments were conducted in a thermal analyzer (Netzsch STA 409 PG Luxx) coupled with a QMS (403C Aëolos). The mass spectrometer used for evolved gas analysis allows the detection of mass numbers between 1 and $300 \mathrm{amu}$ in the SCAN or MID mode. In the TG experiments, the mass change of the metal oxide oxygen carriers was measured isothermally as a function of time. Three reduction/oxidation cycles were conducted at atmospheric pressure to determine the reactivity of the oxygen carriers, and their stability performance was investigated in twenty redox cycles. In hydrogen CLC measurement, approximately $100 \mathrm{mg}$ of sample was placed in an $\mathrm{Al}_{2} \mathrm{O}_{3}$ crucible. $3 \% \mathrm{H}_{2}$ balanced by argon was used for the reduction reaction, and $20 \%$ of oxygen balanced by nitrogen was used for the oxidation reaction, while the reaction gas flow rates were set at 125 and $50 \mathrm{~mL} \mathrm{~min}^{-1}$, respectively. The reduction time was set at $10 \mathrm{~min}$ and the oxidation time at $5 \mathrm{~min}$. To avoid the mixing of reduction gases and air, the system was flushed with argon for $5 \mathrm{~min}$ before and after each reduction/oxidation reaction. To understand the effect of temperature, the cyclic tests were carried out over a temperature range of $600-800{ }^{\circ} \mathrm{C}$. For the long term measurement of twenty cycles at $950{ }^{\circ} \mathrm{C}$, both the reduction time and oxidation time were set at $20 \mathrm{~min}$, and the system was flushed with argon for $5 \mathrm{~min}$ before and after. The reaction gas flow rates were set at 125 and $25 \mathrm{~mL} \mathrm{~min}{ }^{-1}$, respectively. The hydrogen was used as a fuel since it is the major compound of syngas from biomass/coal gasification process [2]. The TG reactions parameters were set experimentally to assure being in kinetic region.

In the baseline coal tests, approximately $200 \mathrm{mg}$ sample was heated in a $\mathrm{Al}_{2} \mathrm{O}_{3}$ crucible with an argon purge to $900{ }^{\circ} \mathrm{C}$ at a heating rate of $15 \mathrm{~K} \mathrm{~min}^{-1}$. Janina coal was used for the reduction segment, and $20 \%$ of oxygen balanced by nitrogen was used for the oxidation segment. Hard coal was physically mixed with the sediment samples. In the TG experiment, the oxygen carrier-to-ash-free coal mass ratio was $25: 1$, which was revealed by previous tests to provide full combustion of hard coal. A 15:1 ratio for partial combustion was also studied. Both the sediments and the coal samples were dried in the balance-drier at 
$115^{\circ} \mathrm{C}$ to determine the water content before the thermogravimetric tests. The mixture of coal and sediments from the potable water purification process was heated to $900{ }^{\circ} \mathrm{C}$ in TG. After the set temperature was reached, the isothermal measurement was performed for $90 \mathrm{~min}$. The oxidizing condition was set at $10 \mathrm{~min}$ for a flow rate of $50 \mathrm{~mL} \mathrm{~min}^{-1}$. For comparison purposes, samples of coal and sediments from potable water purification process were measured individually in the TG under the same experimental conditions as for the mixtures.

The fractional conversions (i.e., the fractional reduction and the fractional oxidation) were calculated from the TG data. The fractional conversion $(X)$ is defined as follows:

Fractional reduction $(X)=\left(M_{\mathrm{oxd}}-M\right)\left(M_{\mathrm{oxd}}-M_{\mathrm{red}}\right)^{-1}$,

Fractional oxidation $(X)=\left(M-M_{\text {red }}\right) /\left(M_{\text {oxd }}-M_{\text {red }}\right)^{-1}$,

where $M$ denotes the instantaneous mass (mass of the metal oxide/coal mixture); $M_{\text {oxd }}$ denotes the mass of a completely oxidized sample in the TG (i.e., completely oxidized oxide/ coal mixture in the TG after introducing air); and $M_{\text {red }}$ denotes the mass of a completely reduced sample in the TG (i.e., the mass of the metal oxide/coal mixture after the reaction). The above contains reduced metal, ash, and unreacted coal. The oxygen uptake percentages were obtained using the TG mass change data in the equation given below:

Percent oxygen consumption

$=($ experimental oxygen consumption

/theoretical capacity of oxygen present

in the metal oxide) $\times 100$.

The reaction rates $(\mathrm{d} X / \mathrm{d} t)$ were calculated by differentiating the mass data versus time and they mean the rates at maximum of DTG peak.

Phase composition

XRD of the ashes of sediments from potable water purification process were obtained using a PAN Analytical X'Pert Pro X-ray diffractometer with $\mathrm{Cu} \mathrm{K}_{\alpha}, \lambda=1.54056 \AA$ 践ation. The diffraction patterns were collected in the $2 \Theta$ range of $10-120^{\circ}$. Data analysis was conducted using HighScore Plus analysis software supplied by PAN Analytical. The ICCSD database was used to identify the phases.

\section{Chemical composition}

The chemical composition of the sediments from the potable water purification process was determined by ICPOES, using a Thermo ICAP 6500 instrument.
The particle size distribution analysis

A Malvern Mastersizer 2000 particle analyzer with a dispersion Hydro $2000 \mathrm{G}$ mouthpiece was used to analyze the particle size distribution. A He-Ne laser with $\lambda=633 \mathrm{~nm}$ was used as a red light source, and a LED laser with $\lambda=466 \mathrm{~nm}$ was used as a blue light source.

Determination of melting behavior

The pelletized samples were placed in an oven (PR $25 / 1750 / \mathrm{PIE}$ ) and heated to $1,650{ }^{\circ} \mathrm{C}$ in a $\mathrm{CO}$ or air atmosphere to observe their melting behavior. The average shrinkage, deformation, and the hemisphere and flow temperatures were determined by an HT camera to observe the change in the pellet shape during the heating process.

Microstructure

The microstructure of the material surface was studied using SEM, using a Nanos Nova 200 instrument (made by Fei Company, Europe) with an EDS supply for chemical micro-analysis. The surface morphology was studied by gluing carbon tape onto the samples; carbon tape was not used in the chemical analysis of the samples. The study was conducted using a low vacuum detector (LVD) at an accelerating voltage between 10 and $18 \mathrm{kV}$.

\section{Results and discussion}

Sample characterization

Characterization of oxygen carrier particles by ICP-OES and XRD

The chemical composition of the Miedary (M) and Bibiela (B) sediment samples was studied by ICP-OES (Table 1). Optical emission spectrometry data showed that the sediments from the potable water purification process mostly consisted of $\mathrm{Fe}_{2} \mathrm{O}_{3}$ (57.8-58.1\%), $\mathrm{SiO}_{2}$ (25.2-30.7\%), $\mathrm{CaO}(3.92-8.43 \%)$, and $\mathrm{Mn}_{3} \mathrm{O}_{4}(0.94-1.39 \%)$. Iron and manganese species may actively participate in CLC as active metal oxides. Inert materials such as silica and alumina can improve the temperature resistance over multiple reduction and oxidation CLC cycles and can also inhibit the agglomeration tendency of iron oxide.

Figure 1 shows the results of the XRD analysis for the fresh oxygen carriers, which are supported by the ICP-OES results. Well-crystallized phases of hematite $\left(\mathrm{Fe}_{2} \mathrm{O}_{3}\right)$ and silica $\left(\mathrm{SiO}_{2}\right)$ were detected. No alumina, manganese, or calcium oxide diffraction peaks were observed. Their absence may be because the concentrations of the oxides in 
Table 1 Chemical analysis of water sediments from Miedary and Bibiela determined by ICP-OES method

\begin{tabular}{llllllllllllll}
\hline & $\mathrm{Fe}_{2} \mathrm{O}_{3}$ & $\mathrm{Al}_{2} \mathrm{O}_{3}$ & $\mathrm{SiO}_{2}$ & $\mathrm{Mn}_{3} \mathrm{O}_{4}$ & $\mathrm{CaO}$ & $\mathrm{MgO} / \%$ & $\mathrm{Na}_{2} \mathrm{O}$ & $\mathrm{K}_{2} \mathrm{O}$ & $\mathrm{P}_{2} \mathrm{O}_{5}$ & $\mathrm{SO}_{3}$ & $\mathrm{ZnO}$ & $\mathrm{Cu}$ & $\mathrm{Loss}$ of ignition \\
\hline Miedary & 58.1 & 0.59 & 25.2 & 0.94 & 8.43 & 0.30 & 0.25 & 0.29 & 2.50 & 0.76 & 0.77 & 0.01 & 0.32 \\
Bibiela & 57.8 & 0.82 & 30.7 & 1.39 & 3.92 & 0.42 & 0.18 & 0.24 & 2.78 & 0.37 & 0.09 & 0.01 & 0.01 \\
\hline
\end{tabular}

the sediment are too low to detect using the X-ray powder diffractometer. Because the sediments from both water supplies showed the same phase composition and similar chemical composition, comparable reactivity might be expected.

\section{Melting behavior and particle size distribution}

The melting points are important parameters in evaluating the agglomeration tendencies of solid-state oxygen carriers. Some loss of reactivity might occur as a result of low melting temperature, which is why their melting behavior was examined. Both natural and synthetic sediment oxygen carriers were tested. High melting points of $1,320-1,330{ }^{\circ} \mathrm{C}$, for $\mathrm{B}$ and $\mathrm{M}$ sediments, respectively, were observed. That high temperature resistance can be considered to be a result of physical-chemical composition, perhaps primarily the presence of silica.

Table 2 shows the particle size distribution analysis results for both as-received and calcined sediments. The asreceived sediments showed that the majority of the sample consisted of fine particles between 20 and $42 \mu \mathrm{m}$. The calcination process that was performed resulting in increasing of particles to 58 and $196 \mu \mathrm{m}$ as indicated by PSD. However, for practical application in fluidized bed CLC system the larger particle size might be required.

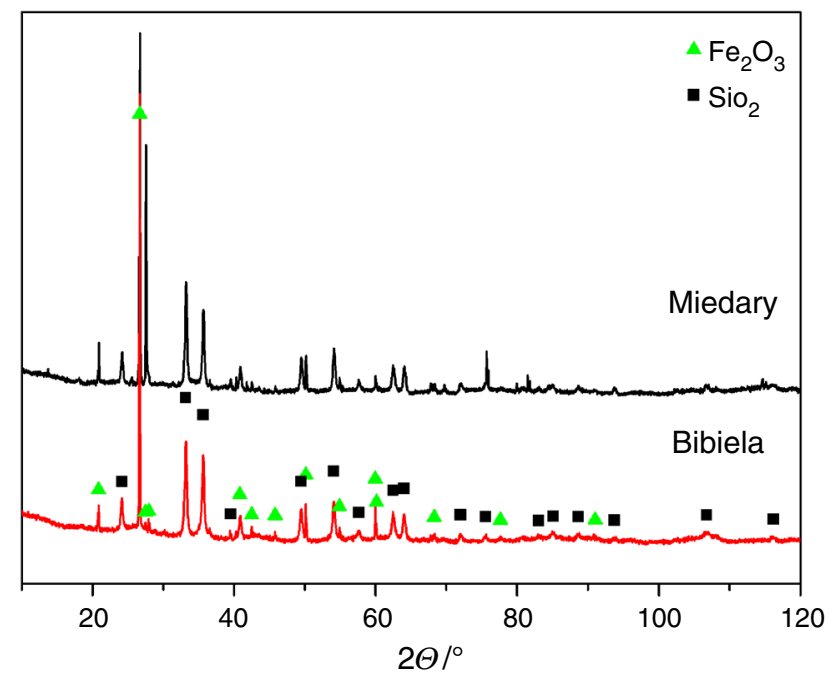

Fig. 1 X-ray powder diffraction pattern of fresh Miedary and Bibiela samples collected at room temperature

\section{Characterization of coal samples}

Hard coal from the Janina coal mine in Poland was selected for solid fuel CLC testing. Prior to the test, ultimate and proximate analyses were carried out. The particle size of the coal samples used in this study was $<200 \mu \mathrm{m}$. The technical analyses of the Janina coal were carried out using LECO TG701, while the elemental analyses were performed on LECO TrueSpec CHN and LECO SC632 analyzers. The combustion heating values were measured using LECO AC200. Table 3 shows the basic quality data on this coal. The Janina coal is a typical power coal and exhibits high reactivity because of its high volatile matter content $(33.5 \%)$.

Oxygen carrier activity study

\section{CLC reaction performance of sediments from potable water with hydrogen}

To evaluate the performance of the natural oxygen carriers, three reduction and oxidation cycles were conducted in TG in a temperature range from 600 to $800{ }^{\circ} \mathrm{C}$, at atmospheric pressure with hydrogen $\left(3 \% \mathrm{H}_{2} / \mathrm{Ar}\right)$. The TG results for Bibiela and Miedary are shown in Fig. 2a and b, respectively. Repeatable performance was observed during the three-cycle test at 600 to $800{ }^{\circ} \mathrm{C}$ temperature range. However, after the first cycle, some loss of the mass during heating occurred. That loss may be a result of water loss and was supported by mass spectrometer data. The amount of oxygen released during reduction was very similar to the amount consumed during oxidation, which indicated that there was $100 \%$ looping of oxygen during these cycles. The stability of the fractional reduction for the all three cycles was the same. The activation of the material was completed after the second reduction/oxidation cycle. For

Table 2 Particle size distribution

\begin{tabular}{llrr}
\hline Sample & \multicolumn{2}{l}{ Size/ $\mu \mathrm{m}$} \\
\cline { 2 - 4 } & $d(0.1)$ & $d(0.5)$ & $d(0.9)$ \\
\hline Miedary (the as-received) & 1.1 & 4.2 & 20.2 \\
Bibiela (the as-received) & 1.1 & 8.0 & 42.0 \\
Miedary (after calcination) & 1.8 & 39.0 & 196.4 \\
Bibiela (after calcination) & 0.6 & 8.4 & 58.4 \\
\hline
\end{tabular}


Table 3 Proximate and ultimate analysis of coal sample

\begin{tabular}{|c|c|c|c|c|c|c|c|c|c|}
\hline \multicolumn{4}{|c|}{ Proximate analysis ad/\% by mass } & \multicolumn{5}{|c|}{ Ultimate analysis ad $/ \%$ by mass } & \multirow[t]{2}{*}{ Low heating value/ $\mathrm{MJ} \mathrm{kg}^{-1}$} \\
\hline Moisture & Volatile & Fixed carbon & Ash & $\mathrm{C}$ & $\mathrm{H}$ & $\mathrm{O}^{\mathrm{a}}$ & $\mathrm{N}$ & $\mathrm{S}$ & \\
\hline 8.8 & 33.5 & 50.8 & 6.9 & 65.2 & 4.00 & 12.9 & 1.01 & 1.11 & 25.32 \\
\hline
\end{tabular}

ad air dried basis

a Calculated by difference
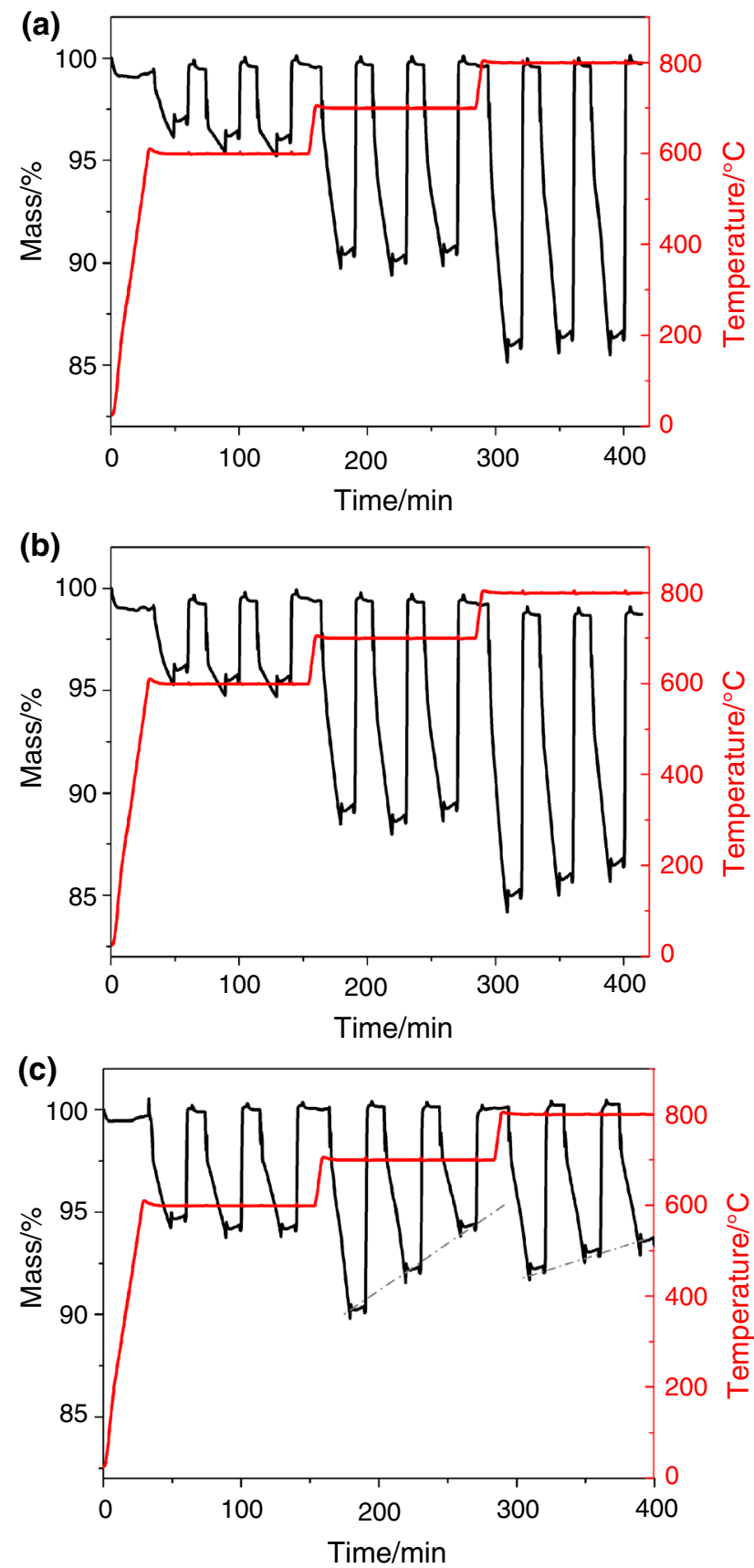

Fig. 2 Three-cycle reduction $\left(3 \% \mathrm{H}_{2}\right)$ /oxidation (air) TG data for a Bibiela, b Miedary and c synthetic sediment at $600-800{ }^{\circ} \mathrm{C}$
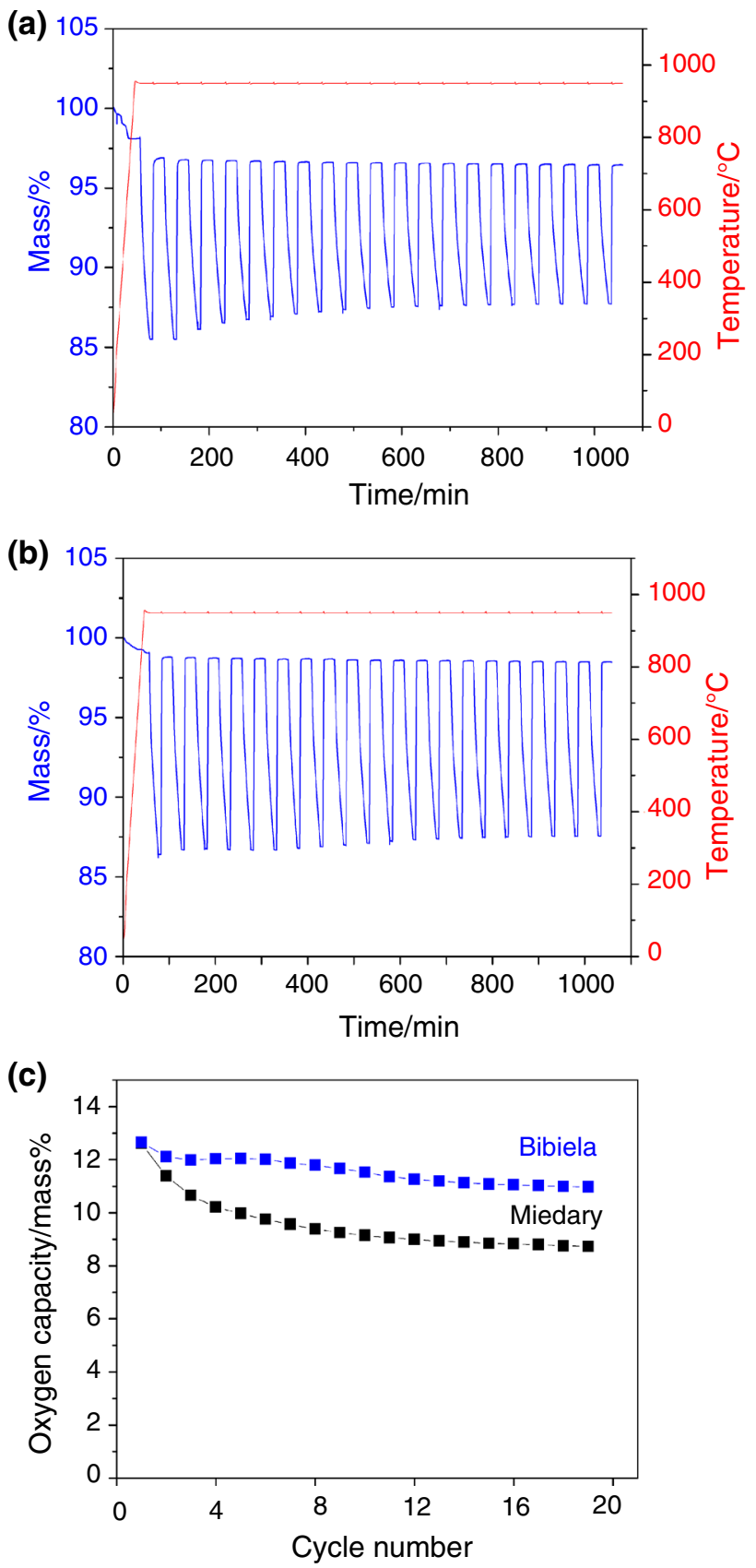

Fig. 3 Long term TG CLC measurement data $\left(3 \% \mathrm{H}_{2}\right)$ /oxidation (air) for a Miedary, b Bibiela at $950{ }^{\circ} \mathrm{C}$ and c oxygen capacity stability at $950{ }^{\circ} \mathrm{C}$ 
comparison purposes, the synthetic sediment was run using the same cyclic conditions, and Fig. $2 c$ shows the TG results. Stable reactivity was observed for $600{ }^{\circ} \mathrm{C}$, but a decrease in reactivity was observed at both 700 and $800^{\circ} \mathrm{C}$. That behavior might be explained by iron silicate formation and was identified previously for $\mathrm{Fe}_{2} \mathrm{O}_{3} / \mathrm{SiO}_{2}$ oxygen carriers $[11,18]$. The observed formation of iron silicate at high temperature during CLC reactions may lead to synthetic carrier deactivation. This result shows the importance of having other support species present when using iron oxide as an oxygen carrier. In the natural oxygen carrier samples, that is, the sediments from potable water, the presence of other elements may prevent the decrease in reactivity, inhibit melting, and better maintain the carriers' reactivity.

In this study, the natural oxygen carriers containing $\mathrm{Fe}_{2} \mathrm{O}_{3}$ and $\mathrm{SiO}_{2}$ demonstrated stable activity, and no deactivation was observed even at higher temperatures, as high as $950^{\circ} \mathrm{C}$ where twenty redox cycles were tested. Figure $3 \mathrm{a}$ and $\mathrm{b}$ shows the TG data collected at $950{ }^{\circ} \mathrm{C}$. The TG data confirm good reactivity and fairly stability for both sediments. Figure $3 \mathrm{c}$ shows the oxygen capacity to be stable with the cycle number, with negligible decrease at the beginning of cycling. Perhaps three to five activation cycles are needed to fully react with the fuel. In that time, the pore structure may be reorganized, and also some water may be lost due to the dehydration reaction at the beginning of cycling.

For that reason, additional TG experiments were carried out for both sediments, heating them to $1000{ }^{\circ} \mathrm{C}$ in an inert $\mathrm{N}_{2}$ atmosphere. The collected data confirmed two mass losses due to water content. The first mass decrease at the maximum dehydration rate was observed at a temperature range of 71 to $76{ }^{\circ} \mathrm{C}$ and was approximately $6 \%$ by mass decrease. Another mass decrease of approximately $5 \%$ by mass at the maximum rate of reaction was observed at 123 to $191{ }^{\circ} \mathrm{C}$ (not shown).

The fractional conversions (i.e., fractional reduction and fractional oxidation) for all cycles were calculated utilizing the TG data. The plots of the fractional reduction of a natural $\mathrm{Fe}$-containing oxygen carrier as a function of time at $600-800{ }^{\circ} \mathrm{C}$ for three successive cycles are shown in Fig. $4 \mathrm{a}-\mathrm{c}$. At a temperature of $600{ }^{\circ} \mathrm{C}$, the data from the first cycle differ considerably from the reduction conversion data for the other two cycles, which may be mainly because of the dehydration reaction in the first cycle. The second and third fractional reduction data showed the same curve progress, and similar behavior was observed at other measurement temperatures. For the $600{ }^{\circ} \mathrm{C}$ TG data, two incline points, marked with asterisks, were observed. The incline points were observed for 0.57 and 0.69 fractional degrees of conversion at 0.49 and 2.32 min of the reduction reaction, respectively. The first slope of the curve may be
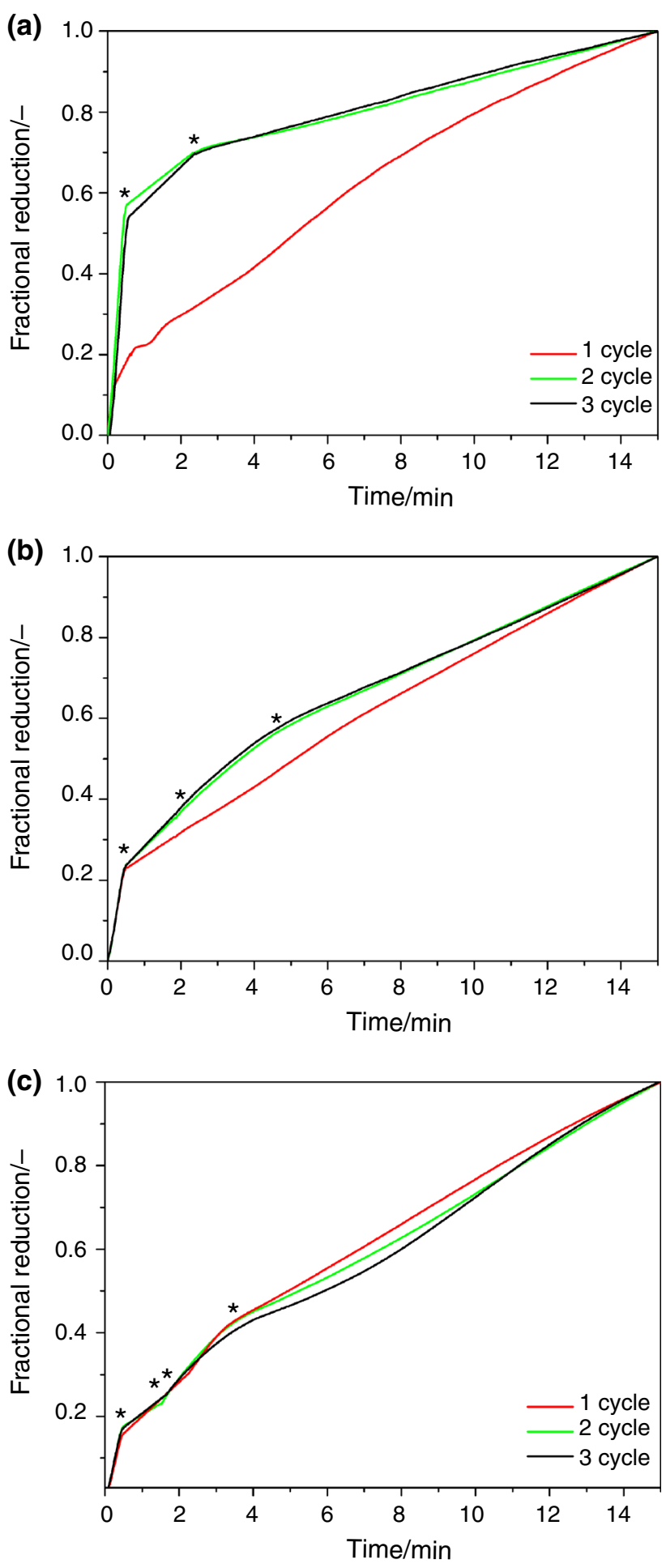

Fig. 4 Fractional reduction as a function of time for Bibiela at a $600{ }^{\circ} \mathrm{C}$, b $700{ }^{\circ} \mathrm{C}$ and $\mathbf{c} 800{ }^{\circ} \mathrm{C}$

attributed to the $\mathrm{Fe}_{2} \mathrm{O}_{3} \rightarrow \mathrm{Fe}_{3} \mathrm{O}_{4}$ reduction reaction, and the next to the $\mathrm{Fe}_{3} \mathrm{O}_{4} \rightarrow \mathrm{FeO}$ reaction. At $700{ }^{\circ} \mathrm{C}$ temperature, the curves showed three regions with different slopes at $0.238,0.353$, and 0.512 reduction conversion degrees. These observations might be attributed to the fast 
Table 4 Oxygen transfer capacity of $\mathrm{Fe}_{2} \mathrm{O}_{3}$-based oxygen carriers under different reduction states

\begin{tabular}{llll}
\hline Reactions & $\begin{array}{l}\text { Theoretical } \\
\text { oxygen transfer } \\
\text { capacity/mass\% }\end{array}$ & $\begin{array}{l}\text { Temperature/ } \\
{ }^{\circ} \mathrm{C}\end{array}$ & $\begin{array}{l}\text { Actual oxygen } \\
\text { transfer } \\
\text { capacity/mass\% }\end{array}$ \\
\hline $\begin{array}{l}3 \mathrm{Fe}_{2} \mathrm{O}_{3} \leftrightarrow \\
2 \mathrm{Fe}_{3} \mathrm{O}_{4}+\end{array}$ & $1.93-1.94$ & 600 & $4.0-4.4$ \\
$1 / 2 \mathrm{O}_{2}$ & & & \\
$\mathrm{Fe}_{2} \mathrm{O}_{3} \leftrightarrow$ & $5.79-5.82$ & 700 & $10.1-10.6$ \\
$2 \mathrm{FeO}+$ & & & \\
$1 / 2 \mathrm{O}_{2}$ & & 800 & 13.9 \\
$\mathrm{Fe}_{2} \mathrm{O}_{3} \leftrightarrow$ & $17.37-17.46$ & & \\
$2 \mathrm{Fe}+$ & & & \\
$3 / 2 \mathrm{O}_{2}$ & & & \\
\hline
\end{tabular}

reduction reaction of $\mathrm{Fe}_{2} \mathrm{O}_{3} \rightarrow \mathrm{Fe}_{3} \mathrm{O}_{4}$, followed by the slower $\mathrm{Fe}_{3} \mathrm{O}_{4} \rightarrow \mathrm{FeO}$ and $\mathrm{FeO} \rightarrow \mathrm{Fe}$. Curves of similar character were observed for a temperature of $800{ }^{\circ} \mathrm{C}$.

Since the adequate oxygen release capacity is crucial for CLC process, therefore, the theoretical oxygen carrying capacities for the natural oxygen carrier sample containing $57.8-58.1 \%$ by mass $\mathrm{Fe}_{2} \mathrm{O}_{3}$ /support at various reduction states were calculated and are shown in Table 4. The oxygen capacity is defined as a mass of oxygen that the oxygen carrier is able to deliver to the fuel. In Other words, higher the oxygen capacity, better the oxygen carrier material.

The theoretical oxygen carrying capacities vary from 1.93 to $17.46 \%$ by mass, depending on the final reduction state of iron species. For the Bibiela and Miedary samples, approximately $4 \%$ by mass decrease was observed during the reaction with $3 \%$ hydrogen at $600{ }^{\circ} \mathrm{C}$ in TG. The small mass change associated with the small oxygen carrier capacity of iron oxide may be related to the $\mathrm{Fe}^{3+} \rightarrow \mathrm{Fe}^{3+/ 2+}$ reduction reaction. The XRD data showed the presence of $\mathrm{Fe}_{2} \mathrm{O}_{3}$ in the fresh sediment samples (Fig. 1), and hence the $\mathrm{Fe}_{2} \mathrm{O}_{3}$ reduction reaction of $\mathrm{Fe}_{2} \mathrm{O}_{3} \rightarrow \mathrm{Fe}_{3} \mathrm{O}_{4}$ is consistent with the TG data. The mass change during the TG reduction reaction for both sediments at $700{ }^{\circ} \mathrm{C}$ showed a high 10.14-10.6\% mass change that might be mainly attributable to the $\mathrm{Fe}_{2} \mathrm{O}_{3} \rightarrow \mathrm{Fe}_{3} \mathrm{O}_{4}$, and $\mathrm{Fe}_{3} \mathrm{O}_{4} \rightarrow \mathrm{FeO}$ reactions and to a lesser degree to the $\mathrm{FeO} \rightarrow \mathrm{Fe}$ reaction, which would be consistent with the progress of the TG data and observed incline points. According to the values reported in Table 4, if $\mathrm{Fe}_{2} \mathrm{O}_{3}$ is present in the sample, this TG reduction mass change of $13.9 \%$ by mass at $800{ }^{\circ} \mathrm{C}$ compares best with the calculations for the reaction $\mathrm{Fe}_{2}$ $\mathrm{O}_{3} \rightarrow 2 \mathrm{Fe}+3 / 2 \mathrm{O}_{2}(17.37-17.46 \%$ by mass). The large oxygen capacity observed based on the TG data indicate that $\mathrm{Fe}_{2} \mathrm{O}_{3}$ is mostly reduced to $\mathrm{Fe}^{0}$, with $\mathrm{Fe}_{2} \mathrm{O}_{3}$ partially reduced to $\mathrm{FeO}$ (Table 4). The oxygen carrying capacity as a function of temperature for both natural and synthetic sediments is shown in Fig. 5. This relationship was assumed from the second reduction cycle at each temperature, with the amount of oxygen used for reduction as a mass $\%$ of the total sample mass. What is interesting is that at a higher temperature, the higher oxygen content might be released from the oxygen carrier structure in both natural and synthetic Fe-based oxygen carrier samples. The data indicate that the oxygen capacity might vary from 4 to $13.9 \%$ by mass for both natural oxygen carriers. However, the synthetic $\mathrm{Fe} / \mathrm{SiO}_{2}$ oxygen carrier showed worse performance than either Miedary or Bibiela. From 600 to $700{ }^{\circ} \mathrm{C}$, the oxygen capacity increased from 5.7 to $7.88 \%$ by mass, then decreased rapidly to $7.14 \%$ by mass at $800{ }^{\circ} \mathrm{C}$. Comparing the performance of the synthetic and natural sediments, it is clear that the natural oxygen carriers show stable reactivity and stable oxygen transport capacity. Additionally, the natural Fe-based material showed a high oxygen content that might be effectively utilized in the CLC reaction. It is believed that even material with only $1 \%$ of oxygen available might be still sufficient for a CLC system with solid fuel [20]. Therefore, using sediments from potable water purification as provide excellent oxygen transport capacity as oxygen carriers, which may make the materials applicable for industrial application.

The fractional oxidation of Bibiela sediment as a function of time at $800{ }^{\circ} \mathrm{C}$ is shown in Fig. 6. The data showed stable regeneration performance with the cycle number. Similar behavior was observed at 600 and $700{ }^{\circ} \mathrm{C}$. At all temperatures, the oxidation reaction was much faster than the reduction reaction. Full sample regeneration was achieved at approximately $2 \mathrm{~min}$. The observed behavior might be explained by both slower hydrogen diffusion through the Fe layers initially formed at the surface of the particles and exposure to a higher concentration of $\mathrm{O}_{2}$ in the oxidative gas compared to the lower concentration of the $\mathrm{H}_{2} / \mathrm{Ar}$ reductive mixture. The reaction rate control resistances of oxidation and reduction of oxygen carrier

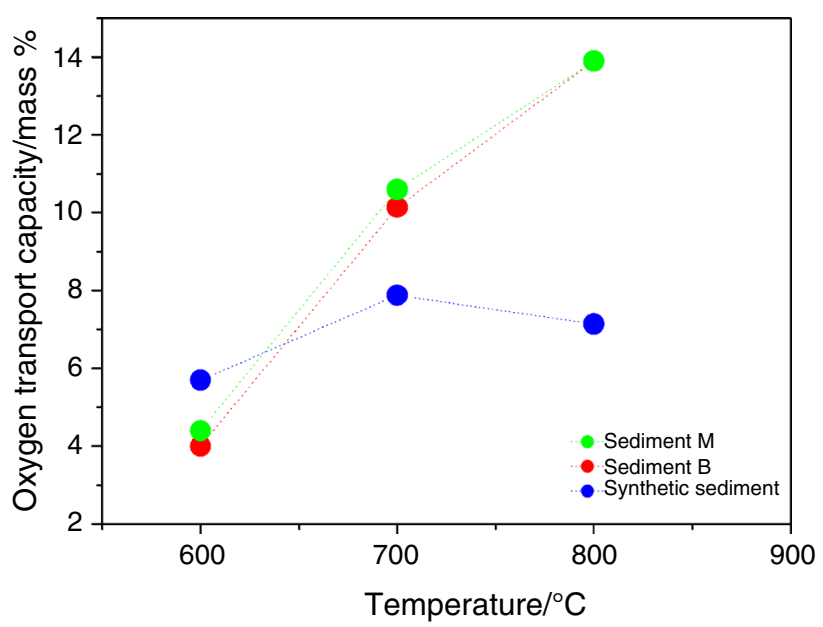

Fig. 5 Oxygen transport capacity in function of temperature 


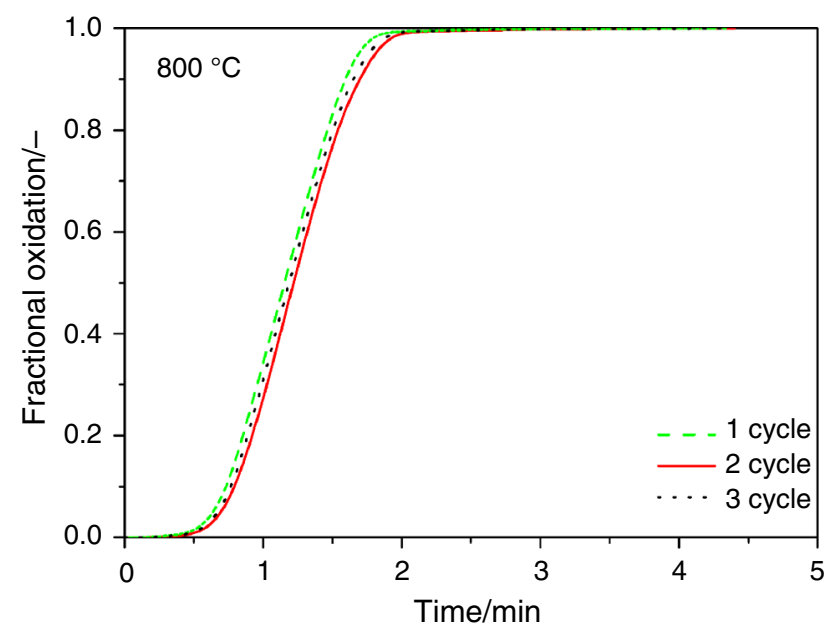

Fig. 6 Fractional oxidation as a function of time for Bibiela sediment

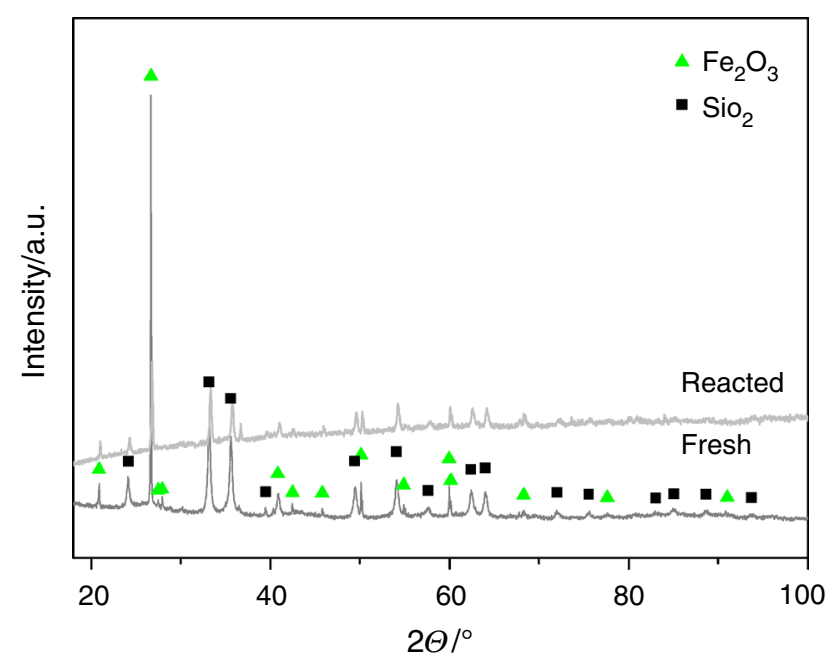

Fig. 7 X-ray powder diffraction pattern of fresh and reacted with $\mathrm{H}_{2}$ Bibiela sample collected at room temperature

particles are different due to different extents of the penetration and diffusion of reactant gas through the $\mathrm{Fe}_{2} \mathrm{O}_{3}$ / $\mathrm{Fe}_{3} \mathrm{O}_{4}$ or $\mathrm{Fe}$ layer. The layer of $\mathrm{Fe}$ is denser than the layer of $\mathrm{Fe}_{2} \mathrm{O}_{3} / \mathrm{Fe}_{3} \mathrm{O}_{4}\left(7.87,5.24 / 5.17 \mathrm{~g} \mathrm{~cm}^{-3}\right.$, respectively). Therefore, in the beginning of the reduction cycle, the hydrogen removes the loose layer of $\mathrm{Fe}_{2} \mathrm{O}_{3}$ and reducing gases find it difficult to penetrate to the inside of the particles through the resulting dense layer of metallic iron to react with the internal metal oxide. Nevertheless, during the oxidation reaction, the thickness of the loose $\mathrm{Fe}_{2} \mathrm{O}_{3}$ / $\mathrm{Fe}_{3} \mathrm{O}_{4}$ layer increases with time, and the penetration and diffusion of $\mathrm{O}_{2}$ through the loose $\mathrm{Fe}_{2} \mathrm{O}_{3} / \mathrm{Fe}_{3} \mathrm{O}_{4}$ layer becomes much easier.

To evaluate regeneration ability, the XRD patterns of the used oxygen carriers were recorded at room temperature (Fig. 7). The XRD data did not show any phase transformation that can occur after the oxidation of reduced samples. Thus, the naturally occurring Fe-containing oxygen carrier successfully maintained its crystal structure under multiple reduction/oxidation cycles.

The CLC activity of synthetic oxygen carrier of $\mathrm{Fe}_{2} \mathrm{O}_{3} /$ $\mathrm{SiO}_{2}$ was also tested at $600-800{ }^{\circ} \mathrm{C}$ for three cycles at each temperature. The results are shown in Fig. 2c. Stable performance was observed at $600{ }^{\circ} \mathrm{C}$, while a continuous decrease in oxygen transport capacity and reactivity was observed during three cycles at $700-800{ }^{\circ} \mathrm{C}$. That behavior may be attributed to the interaction of hematite and silica. As the XRD and SEM data revealed, some silicate crystals were formed. The formation of metallic Fe that reacts with the support may contribute to the lower stability. The support and metal interactions may decrease the capacity with added cycles, and these interactions are generally higher at higher temperatures, and therefore, those experiments led to synthetic sample deactivation and caused only partial regeneration.

Table 5 shows the oxygen uptake values at various temperatures for the naturally occurring $\mathrm{Fe}_{2} \mathrm{O}_{3} / \mathrm{SiO}_{2}$ and the synthetic samples, calculated on the basis of the second cycle TG data. The amounts of oxygen released during reduction are consistent with the amounts consumed during oxidation. The calculated data show that the oxygen uptake strongly depended on the CLC reaction temperature. At $600{ }^{\circ} \mathrm{C}$, 23.4-25.3\% of the oxygen available was used for hydrogen combustion. At $700{ }^{\circ} \mathrm{C}$, the percentage of oxygen utilized for the reaction doubled to approximately $60.9-59.3 \%$. At $800{ }^{\circ} \mathrm{C}$, almost $79.9-81.0 \%$ of the oxygen available was used for the combustion reaction. The opposite performance was observed for the synthetic $\mathrm{Fe} / \mathrm{SiO}_{2}$ oxygen carrier: at the beginning of CLC test, the oxygen utilization increased with temperature, then decreased significantly with further increases in temperature. The oxygen uptake values were 32.8 for $600{ }^{\circ} \mathrm{C}$ and $45.3 \%$ for $700{ }^{\circ} \mathrm{C}$. However, at higher temperature, an intensive decrease to $41.0 \%$ was observed. Therefore, the reactivity results for the sediments from potable water indicated the advantages of using natural oxygen carriers: lower cost, availability and better reactivity and stability over multiple redox cycles compared with synthetic iron-based oxygen carrier material. Due to the high oxygen content available for the CLC reaction, the preferred temperature for combustion with Fe-based sediments should be at least $800{ }^{\circ} \mathrm{C}$, to maximize both the oxygen capacity utilized for the redox reaction and reaction rates. Because in thermal systems, the $\mathrm{Fe}_{2} \mathrm{O}_{3} / \mathrm{Fe}_{3} \mathrm{O}_{4}$ reaction is expected to be applied, there is still a remarkable oxygen capacity for naturally occurring carriers [17, 22].

The data indicated, that water treatment residue contained of $\mathrm{Fe}$ oxides might be effective materials for oxygen carriers for hydrogen (from biomass/coal gasification) CLC in energy systems at $700-950{ }^{\circ} \mathrm{C}$, that also allows significant reduction of both $\mathrm{CO}_{2}$ and $\mathrm{NO}_{x}$ to the atmosphere. 
Table 5 Percentage of oxygen utilized for reaction at the second cycle in $\mathrm{H}_{2}$ at different temperatures

\begin{tabular}{llll}
\hline Temperature $/{ }^{\circ} \mathrm{C}$ & \multicolumn{3}{l}{ Free oxygen usage/\% } \\
\cline { 2 - 4 } & Miedary & Bibiela & Synthetic \\
\hline 600 & 25.3 & 23.4 & 32.8 \\
700 & 60.9 & 59.3 & 45.3 \\
800 & 79.9 & 81.0 & 41.0 \\
\hline
\end{tabular}

CLC reaction performance of natural sediments

from the potable water purification process with hard coal as a solid fuel

As one of the options for CLC is direct coal combustion, one cycle of TG reduction/oxidation tests was performed. Because the direct combustion of metal oxide and carbon is thermodynamically favorable at high temperatures, the combustion reaction was performed at $900{ }^{\circ} \mathrm{C}$. The coal/ metal oxide mixtures were prepared as discussed in the sample preparation section.

Figure 8 shows the mass profile and reaction rate obtained by differentiating the mass data for the combustion of coal with oxygen from sediments from the potable water purification process (25:1, and 15:1 mass ratio) in the TG.

The small mass decrease at the beginning of the reduction reaction of 25:1 oxygen carrier/coal mixture corresponds to water from the coal dehydration. The maximum rate of dehydration occurred at $89.4{ }^{\circ} \mathrm{C}$, which contributed to a $0.47 \%$ mass change and which exhibited a maximum reaction rate of $0.0548 \% \mathrm{~min}^{-1}$. The thermogravimetric data were also supported by the mass spectrometer data $\left(\mathrm{H}_{2} \mathrm{O}\right.$ signal). The outlet $\mathrm{CO}_{2}, \mathrm{H}_{2} \mathrm{O}, \mathrm{CO}$, and $\mathrm{H}_{2}$ concentrations were measured by MS during the direct coal CLC testing. After dehydration, two further mass changes were observed. These changes corresponded to a hard coal volatilization, for which the maximum rate occurred at $442.8^{\circ} \mathrm{C}$, and a coal combustion reaction, for which two maximum reaction rates occurred at 819.5 and $902.1{ }^{\circ} \mathrm{C}$. The calculated reduction reaction rates showed that the fastest was combustion, followed by volatilization and then dehydration, which exhibited maximum rates of $0.5355,0.2688,0.1422$, and $0.0548 \% \mathrm{~min}^{-1}$, respectively. The rates of the two-stage oxidation reaction were estimated as 1.3273 and $0.9187 \% \mathrm{~min}^{-1}$, which was significantly faster than the reduction reaction rates. The total mass increase was estimated at $5.04 \%$ by mass.

The TG data profile for a 15:1 oxygen carrier/coal mixture is also shown in Fig. 8. The small mass decrease at the beginning of the mixture heating in the TG instrument was attributed to coal dehydration. The maximum rate of dehydration occurred at $93.5^{\circ} \mathrm{C}$, which contributed to a small 0.3 mass $\%$ decrease with a reaction rate of $0.0419 \% \mathrm{~min}^{-1}$. Other mass changes were also observed. They corresponded to hard coal volatilization, with the maximum volatilization reaction rate at $441^{\circ} \mathrm{C}$, and to coal combustion, with maximum rates exhibited at $656.5,837.3$, and $937.3{ }^{\circ} \mathrm{C}$. The calculated reduction reaction rates showed that the fastest reaction was combustion, followed by volatilization and dehydration, which exhibited maximum rates of $0.4622,0.3344$, and $0.1873 \% \mathrm{~min}^{-1}$ (combustion), $\quad 0.0935 \% \mathrm{~min}^{-1}$ (volatilization) and $0.0419 \% \mathrm{~min}^{-1}$ (dehydration).

The mass gained by the sample during the regeneration reaction was consistent with the amount of oxygen present in the natural sediment samples. This result indicated that the reduced natural Fe-based oxygen carrier could be successfully re-oxidized at $900{ }^{\circ} \mathrm{C}$. The oxidation reaction was a two-stage process, for which the oxidation reaction rates were 1.0019 and $0.8577 \% \mathrm{~min}^{-1}$. The former is fast and the latter slower, as the $\mathrm{Fe}^{0} \rightarrow \mathrm{Fe}^{2+} \rightarrow \mathrm{Fe}^{3+/ 2+}$
Fig. 8 Coal combustion with oxygen released from Bibiela sediment for $25: 1$ and 15:1 mass ratios

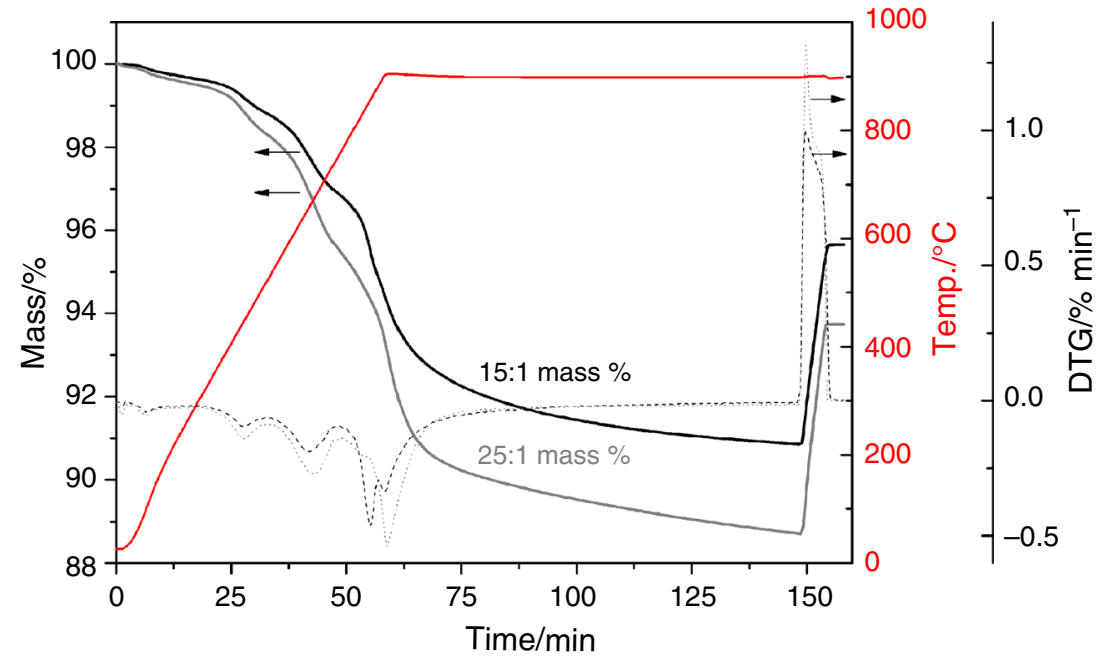


Fig. 9 SEM microphotographs for $\mathbf{a}$ fresh and $\mathbf{b}$, $\mathbf{c}$ reacted Bibiela samples
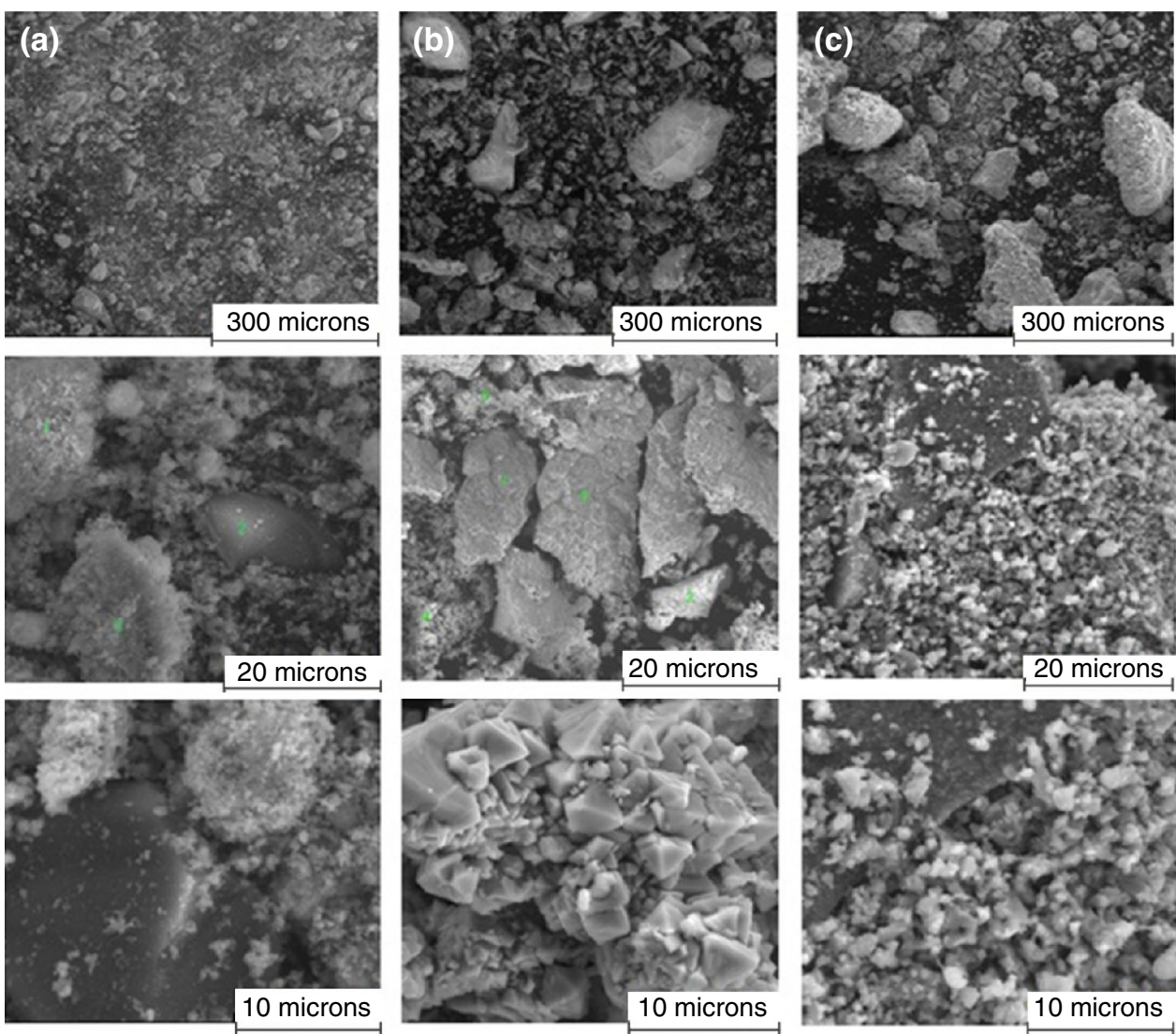

(majority) together with $\mathrm{Fe}^{0} \rightarrow \mathrm{Fe}^{2+}$ (traces) and $\mathrm{Fe}^{3+/ 2+}$ $\rightarrow \mathrm{Fe}^{3+}$ of reactions occurs. The total mass increase was estimated to be $5.04 \%$ by mass. The calculated percentage of oxygen uptake was obtained using the mass change data from the TG. The Janina coal combustion TG results indicated that 29.99 and $29.52 \%$ of the oxygen available were used for combustion reactions. The regeneration reaction rates were faster by a factor of 1.3 for the 25:1 oxygen carrier/coal mixture, compared to the rates for the 15:1 ratio mixture. Both combustion reactions were also faster by a factor of 1.1-1.2. The reason might be the amount of oxygen available, which was larger in the previous mixture. The results indicated that the excess of oxygen improved the reactivity of the coal/sediment mixture. The sediments from the potable water purification process were successfully re-oxidized, as no detectable formation of compounds of iron oxide and coal ash was observed by XRD analysis.

The similar observation for bi-metallic $\mathrm{Fe}-\mathrm{Cu}$-based oxides with higher amount of $\mathrm{Fe}$ was reported elsewhere [12]. The bi-metallic oxygen carriers were more ashresistant compared with these oxygen carriers that are based on mono-metallic $\mathrm{Ni}$, or $\mathrm{Cu}$ oxides carriers [27]. Therefore, the Fe-based sediment from water purification process has a great potential to be the excellent candidates for application for direct coal combustion process, since no interaction with Janina coal ash was observed.

Based on the TG results for raw Janina coal that was run separately in TG under the same experimental conditions as for mixtures, the reaction rates were 0.24 , 0.80 , and $1.26 \% \mathrm{~min}^{-1}$ for dehydration, pyrolysis, and coal combustion in air, respectively (not shown). The maximum rate of coal dehydration occurred at $80^{\circ} \mathrm{C}$. The TG data showed the $3.85 \%$ mass decrease, which agreed well with the observed water MS profile. Afterward, the hard coal volatilization reaction was initiated at approximately $280{ }^{\circ} \mathrm{C}$ with the maximum reaction rate occurring at $440{ }^{\circ} \mathrm{C}$. That broad peak ended at $640{ }^{\circ} \mathrm{C}$ with a mass change of $27.15 \%$ by mass. The combustion of the char was carried out with a total mass change of $36.99 \%$ by mass. The calculated rates for the reduction reaction showed that the fastest was the combustion reaction, followed by the volatilization and dehydration reactions, with maximum reaction rates of $0.271,0.211$, and $0.136 \% \mathrm{~min}^{-1}$, respectively. For the sediments from the potable water purification process that were also run separately in TG under the same experimental conditions as for the mixtures, almost constant mass was observed within the TG measurements (not shown). 
Siriwardane et al. [27] showed that for an $\mathrm{Fe}_{2} \mathrm{O}_{3} /$ Illinois \#6 coal system, the maximum combustion rate occurred over a temperature range from 973 to $977^{\circ} \mathrm{C}$. They reported that approximately $95 \%$ combustion could be attained using pure, synthetic $\mathrm{Fe}_{2} \mathrm{O}_{3}$. The percentage of oxidation was approximately $77 \%$ with a change in the $\mathrm{Fe}$ oxidation state from $\mathrm{Fe}^{3+}$ to $\mathrm{Fe}^{2+}$ during the CLC reaction. Our data showed that to obtain full combustion at an appreciable reaction rate, a reaction temperature within an approximate temperature range from 800 to $910{ }^{\circ} \mathrm{C}$ that is lower than shown in [27], would be required for the $\mathrm{Fe}_{2} \mathrm{O}_{3}$ oxygen carrier/coal system based on sediments from potable water.

In general, it is concluded that direct coal combustion requires a suitable reaction temperature, an appropriate amount of an oxygen carrier and good surface contact between the carrier and the coal to obtain full combustion at an appreciable reaction rate. In other cases, low reaction rates might be expected, due to diffusion limits and complicated gas penetration through the $\mathrm{FeO} / \mathrm{Fe}_{3} \mathrm{O}_{4} / \mathrm{Fe}_{2} \mathrm{O}_{3}$ oxide layers. For practical power generation in a real CLC system, the other solution for small reaction rates of solid fuel with Fe species might be applied, i.e., by replacing the coal/biomass with, for example, coal/biomass steam gasification syngas. Some examples of that option were also recommended elsewhere [11, 23, 27].

\section{The microstructure of the material surface}

The surface of both (a) the fresh and $(b-c)$ used sediment oxygen carriers was analyzed in a SEM. Figure 9 shows the photomicrographs for Bibiela at different magnifications $(350 \times, 5000 \times$, and $10,000 \times)$. The photomicrographs of the fresh sediment samples (Fig. 9a) presented granular morphology with grain sizes from 11 to $40 \mu \mathrm{m}$. Analysis of the big grain that surface was smooth and homogeneous confirmed to be $\mathrm{SiO}_{2}$. The chemical analysis of feathery structure grain type indicated the presence of phases with a high content of $\mathrm{Fe}$ and $\mathrm{O}$ and trace amounts of other oxides, such as $\mathrm{SiO}_{2}, \mathrm{CaO}$, $\mathrm{Mn}_{3} \mathrm{O}_{4}, \mathrm{Al}_{2} \mathrm{O}_{3}, \mathrm{MgO}$, and $\mathrm{P}_{2} \mathrm{O}_{5}$. These results were confirmed by ICP-OES analysis, and also by PSD analysis results. The PSD results also showed diverse grain sizes that are detected as separate phases of $\mathrm{Fe}_{2} \mathrm{O}_{3}, \mathrm{SiO}_{2}$, and $\mathrm{CaO}$.

The photomicrographs for the naturally occurring oxygen carriers reacted for 20 cycles with $\mathrm{H}_{2}$ (Fig. 9b) and then regenerated showed large and small particles from 20 to $160 \mu \mathrm{m}$. A quantitative analysis confirmed the presence of a phase rich in $\mathrm{Fe}$ and $\mathrm{O}$ with trace amounts of $\mathrm{Ca}, \mathrm{Si}, \mathrm{P}$, and $\mathrm{Mn}$. The sample showed a greater increase in porosity than before the cycling redox test. After the combustion and oxidation reactions, SEM images of the oxygen carrier indicated a closed-site, with zeolites like crystalline structures with a smoother surface and an increase in particle size, while others showed rhombohedral crystal structure morphology.

At $900{ }^{\circ} \mathrm{C}$, both oxygen carrier/coal ratio samples showed increased grain size because reactions with the coal occurred. Figure 9c shows SEM pictures of the sediment after reaction with coal for 15:1 ratio. The grain size ranged from a few to $160 \mu \mathrm{m}$. Irregularly shaped grains with large surface area, rich in $\mathrm{Fe}$ and $\mathrm{O}$ with traces of $\mathrm{Ca}, \mathrm{Mn}, \mathrm{Si}$, and $\mathrm{P}$ were observed. The SEM pictures show the small forms of a pseudo-crystalized granular fraction.

SEM photomicrographs showed the sub-granular structure of the grains on the surfaces of the reacted oxygen carrier, where the porosity of the particles has significantly increased after the CLC reactions with both hydrogen and coal. Increased particle size was also observed. Furthermore, a similar effect was observed in previous work [18]. In the investigations on Chinese bituminous coal combustion with CVRD iron ore, the SEM analyses also showed that the iron ore particles became porous after cycling. Moreover, the presence of $\mathrm{SiO}_{2}$ and of other elements ( $\mathrm{CaO}, \mathrm{Mn}_{3} \mathrm{O}_{4}$ etc.) as indicated in Table 1 was confirmed by SEM. Perhaps they inhibited thermal sintering of the oxygen carrier particles and helped to maintain their stable performance during combustion reactions.

\section{Conclusions}

The aim of this study was to use of sediments from potable water purification as oxygen carriers in chemical looping for clean energy generation. The XRD and ICP-OES data revealed that the sediments were mostly composed of $\mathrm{Fe}_{2} \mathrm{O}_{3}$ and $\mathrm{SiO}_{2}$, but also contained some minor oxides, such as $\mathrm{Al}_{2} \mathrm{O}_{3}$ and $\mathrm{Mn}_{3} \mathrm{O}_{4}$, that can be attractive in a chemical looping material.

Three reduction and oxidation cycles over $600-800{ }^{\circ} \mathrm{C}$ using a TG instrument showed that inexpensive material may be practical for use in a CLC system. Sediments from potable water purification showed excellent oxygen transport capacity of $13.9 \%$ at $800{ }^{\circ} \mathrm{C}$ with $\mathrm{H}_{2}$ (from biomass/ coal gasification process). They also showed good regeneration ability, confirmed by both TG and XRD experiments. The stable cyclic performance was also confirmed at $950{ }^{\circ} \mathrm{C}$ over twenty cycles with $3 \% \mathrm{H}_{2} / \mathrm{Ar}$ and air. A strong positive temperature effect on reactivity was observed for the natural $\mathrm{Fe}_{2} \mathrm{O}_{3} / \mathrm{SiO}_{2}$ oxygen carrier. For both of the tested sediments (Bibiela and Miedary), the reduction reaction rate and oxygen transport capacity increased significantly with increasing temperature, while for the synthetic $\mathrm{Fe}_{2} \mathrm{O}_{3} / \mathrm{SiO}_{2}$ oxygen carrier, decreases in the rate and oxygen capacity were observed. These results occurred due to silicate formation during the cyclic redox reaction for the synthetic carrier, while for the natural 
sediments, other elements $\left(\mathrm{CaO}, \mathrm{Mn}_{3} \mathrm{O}_{4}\right)$ may have helped to maintain their reactivity and prevented the silicate formation (Table 1). Contrary, the naturally occurring Febased oxygen carriers showed excellent stability for CLC reactions with hydrogen and coal. Compared to the synthetic $\mathrm{Fe}_{2} \mathrm{O}_{3} / \mathrm{SiO}_{2}$ oxygen carriers, the natural carriers that are $\mathrm{Fe}$-based residue showed both higher and more stable oxygen capacity, along with more stable performance.

The TG results showed that sediments at a 25:1 and $15: 1 \%$ by mass ratio with coal at $900{ }^{\circ} \mathrm{C}$ might fully combust the coal in a direct CLC reaction. Our data showed that to obtain full combustion at an appreciable rate, a reaction temperature of approximately $900{ }^{\circ} \mathrm{C}$ would be required for the $\mathrm{Fe}_{2} \mathrm{O}_{3} /$ coal system based on sediments from water purification. The data proved that the sediments are also ash resistant, that should be a superior consideration, while a direct coal CLC reaction in a real power system is applied.

Moreover, also good physical properties suitable for the energy generation process in CLC system as high melting temperature of approximately $1,320{ }^{\circ} \mathrm{C}$ were observed. These oxygen carriers' most attractive feature may be their exceptional low cost of manufacture and the fact that they are freely available worldwide. Moreover, it would be more economical to use them as oxygen carriers compared to synthetic materials, especially where oxygen carriers have a limited lifetime or could even be lost during circulation in a CLC reactor.

The promising results of the reactivity study by $\mathrm{TG}$ showed that many of the sediments that are waste, might be potentially and successfully reused in the future. Fe-based naturally occurring oxygen carriers are effective carriers for hydrogen fueled CLC (a part of syngas) at $700-950{ }^{\circ} \mathrm{C}$ and for direct coal combustion at approximately $900{ }^{\circ} \mathrm{C}$ for energy systems, that also enables significant reduction of both $\mathrm{CO}_{2}$ and $\mathrm{NO}_{x}$ emissions to the atmosphere.

Acknowledgements The work was partially founded by Polish Ministry of Higher Educational and Science, Contract Number 5/PMPP/U/1-09.10/E-134/2011. The author is gratefully to Upper Silesian Enterprise of Water Supply Joint Stock to make samples available.

Open Access This article is distributed under the terms of the Creative Commons Attribution License which permits any use, distribution, and reproduction in any medium, provided the original author(s) and the source are credited.

\section{References}

1. Ishida $\mathrm{M}$, Jin $\mathrm{H}$. A novel chemical looping combustor without $\mathrm{NO}_{x}$ formation. Ind Eng Chem Res. 1996;35:2469-72.

2. Kobayashi N, Fan LS. Biomass direct chemical looping process: a perspective. Biomass Bioenergy. 2011;35:1252-62.
3. Hossain MM, de Lasa HI. Chemical-looping combustion (CLC) for inherent $\mathrm{CO}_{2}$ separations-a review. Chem Eng Sci. 2008;63:4433-51.

4. Cui X, Zhang X, Feng Y, Wang G, Yang M, Gao H, Luo W. Effect of partial substitution of $\mathrm{Ca}$ in $\mathrm{LaMnO}_{3}$ on coal catalytic combustion. J Therm Anal Calorim. 2013;112:719-26.

5. Song T, Wu J, Shen L, Xiao J. Experimental investigation on hydrogen production from biomass gasification in interconnected fluidized beds. Biomass Bioenergy. 2012;36:258-67.

6. Nalbandian L, Evdou A, Zaspalis V. $\mathrm{La}_{1-x} \mathrm{Sr}_{x} \mathrm{M}_{y} \mathrm{Fe}_{1-y} \mathrm{O}_{3-\delta}$ perovskites as oxygen carrier materials for chemical-looping reforming. Int J Hydrogen Energy. 2011;36:6657-70.

7. Wu X, Zhou K, Wu W, Cui X, Li Y. Magnetic properties of nanocrystalline $\mathrm{CuFe}_{2} \mathrm{O}_{4}$ and kinetics of thermal decomposition of precursor. J Therm Anal Calorim. 2013;111:9-16.

8. Azad AM, Hedayati A, Ryden M, Leion $H$, Mattisson $T$. Examining the $\mathrm{Cu}-\mathrm{Mn}-\mathrm{O}$ spinel system as an oxygen carrier in chemical looping combustion. Energy Technol. 2013; 1:59-69.

9. Ksepko E, Siriwardane RV, Tian H, Simonyi T, Sciazko M. Effect of $\mathrm{H}_{2} \mathrm{~S}$ on chemical looping combustion of coal-derived synthesis gas over $\mathrm{Fe}-\mathrm{Mn}$ oxides supported on sepiolite $\mathrm{ZrO}_{2}$ and $\mathrm{Al}_{2} \mathrm{O}_{3}$. Energy Fuels. 2012;26(4):2461-72.

10. Zhao H, Cao Y, Orndorff W, Pan W. Study on modification of $\mathrm{Cu}$-based oxygen carrier for chemical looping combustion. J Therm Anal Calorim. 2013;113:1123-8.

11. Eyring EM, Konya G, Lighty JS, Sahir A, Sarofim A, Whitty K. Chemical looping with copper oxide as carrier and coal as fuel. Oil Gas Sci Technol. 2011;66:209-21.

12. Ksepko E, Grzegorz Ł. Effective direct chemical looping coal combustion with bi-metallic $\mathrm{Fe}-\mathrm{Cu}$ oxygen carriers studied using TG-MS techniques. J Therm Anal Calorim. 2014;. doi:10.1007/ s10973-014-3674-x.

13. Adanez J, Cuadrat A, Abad A, Gayan P, de Diego LF, Garcia Labiano F. Ilmenite activation during consecutive redox cycles in chemical looping combustion. Energy Fuels. 2010;24: 1402-13.

14. Kolbitsch P, Pröll T, Bolhar-Nordemkampf J, Hofbauer $H$. Operating experience with chemical looping combustion in a $120 \mathrm{~kW}$ dual circulating fluidized bed (DCFB) unit. Int J Greenh Gas Control. 2010;4:180-5.

15. Rydén M, Johansson M, Cleverstam E, Lyngfelt A, Mattisson T. Ilmenite with addition of $\mathrm{NiO}$ as oxygen carrier for chemical looping combustion. Fuel. 2010;89:3523-33.

16. den Hoed P, Luckos A. Oxidation and reduction of iron titanium oxides in chemical looping combustion: a phase chemical description. Oil Gas Sci Technol. 2011;66:249-64.

17. Tian H, Siriwardane R, Simonyi T, Poston J. Natural ores as oxygen carriers in chemical looping combustion. Energy Fuels. 2013;27:4108-18.

18. Xiao R, Song Q, Zhang S, Zheng W, Yang Y. Pressurized chemical looping combustion of Chinese bituminous coal: cyclic performance and characterization of iron ore based oxygen carrier. Energy Fuels. 2010;24:1449-63.

19. Leion H, Jerndal E, Steenari BM, Hermansson S, Israelsson M, Jansson E, Johnsson M, Thunberg R, Vadenbo A, Mattisson T, Lyngfelt A. Solid fuels in chemical looping combustion using oxide scale and unprocessed iron ore as oxygen carriers. Fuel. 2009;88:1945-54.

20. Leion H, Mattisson T, Lyngfelt A. Use of ores and industrial products as oxygen carriers in chemical looping combustion. Energy Fuels. 2009;23:2307-15.

21. Mendiara T, Abad A, de Diego LF, García Labiano F, Gayán P, Adanez J. Use of an Fe-based residue from alumina production as an oxygen carrier in chemical looping combustion. Energy Fuels. 2012;26:1420-31. 
22. Fossdal A, Bakken E, Oeye BA, Schoening C, Kaus I, Mokkelbost T, Larring Y. Study of inexpensive oxygen carriers for chemical looping combustion. Int $\mathrm{J}$ Greenh Gas Control. 2011;5:483-8.

23. Zhang S, Saha C, Yang Y, Bhattacharya S, Xiao R. Use of $\mathrm{Fe}_{2} \mathrm{O}_{3}$ containing industrial wastes as the oxygen carrier for chemical looping combustion of coal: effects of pressure and cycles. Energy Fuels. 2011;25:4357-66.

24. Ksepko E. Sewage sludge ash as an alternative low-cost oxygen carrier for chemical looping combustion. J Therm Anal Calorim. 2014; 116:1395-407.
25. Tsakalakis KG. Scrap tyres management in the EU cement industry - an economic/environmental approach. ZKG. 2007;4:43-55.

26. 2011 Edition of the drinking water standards and health advisories EPA 820-R-11 002. Office of Water US Environmental Protection Agency, Washington DC.

27. Siriwardane R, Tian H, Richards G, Simonyi T, Poston J. Chemical looping combustion of coal with metal oxide oxygen carriers. Energy Fuels. 2009;23:3885-92. 